University of Texas at El Paso

ScholarWorks@UTEP

6-2017

\title{
In Education, Delayed Feedback Is Often More Efficient Than Immediate Feedback: A Geometric Explanation
}

\author{
Francisco Zapata \\ The University of Texas at El Paso, fazg74@gmail.com \\ Olga Kosheleva \\ The University of Texas at El Paso, olgak@utep.edu \\ Vladik Kreinovich \\ The University of Texas at El Paso, vladik@utep.edu
}

Follow this and additional works at: https://scholarworks.utep.edu/cs_techrep

Part of the Education Commons, and the Mathematics Commons

Comments:

Technical Report: UTEP-CS-17-52

Published in Journal of Innovative Technology and Education, 2017, Vol. 4, No. 1, pp. 109-112.

\section{Recommended Citation}

Zapata, Francisco; Kosheleva, Olga; and Kreinovich, Vladik, "In Education, Delayed Feedback Is Often More Efficient Than Immediate Feedback: A Geometric Explanation" (2017). Departmental Technical Reports (CS). 1145.

https://scholarworks.utep.edu/cs_techrep/1145

This Article is brought to you for free and open access by the Computer Science at ScholarWorks@UTEP. It has been accepted for inclusion in Departmental Technical Reports (CS) by an authorized administrator of ScholarWorks@UTEP.For more information, please contact Iweber@utep.edu. 


\title{
In Education, Delayed Feedback Is Often More Efficient Than Immediate Feedback: A Geometric Explanation
}

\author{
Francisco Zapata ${ }^{1}$, Olga Kosheleva ${ }^{2}$, and Vladik Kreinovich ${ }^{3}$ \\ ${ }^{1}$ Department of Industrial, Manufacturing, and \\ Systems Engineering \\ ${ }^{2}$ Department of Teacher Education \\ ${ }^{3}$ Department of Computer Science \\ University of Texas at El Paso \\ $500 \mathrm{~W}$. University \\ El Paso, Texas 79968, USA \\ fazg74@gmail.com, olgak@utep.edu,vladik@utep.edu
}

\begin{abstract}
Feedback is important in education. It is commonly believed that immediate feedback is very important. That is why instructors stay often late at night grading students' assignments - to make sure that the students get their feedback as early as possible. However, surprisingly, experiments show that in many cases, delayed feedback is more efficient that the immediate one. In this paper, we provide a simple geometric explanation of this seemingly counter-intuitive empirical phenomenon.
\end{abstract}

\section{Formulation of the Problem}

In education, intermediate feedback is useful. Empirical data shows that intermediate feedback helps in education. Namely, the very existence of an intermediate test significantly improves the learning outcomes in comparison with the situation when students only learn about their level of knowledge from the final exam; see, e.g., [2].

In [4], we describe a simple geometric model of learning that explains this improvement - and even explains the percentage by which the learning outcomes improve.

Shall feedback be immediate or somewhat delayed? Since the feedback provided right after the test is better for learning that the feedback provided only at the end of the class, it seems reasonable to conjecture that the smaller 
the delay, the more efficient the feedback. In other words, it seems reasonable to expect that immediate feedback is better than the slightly delayed one.

However, empirical data shows the opposite effect: a feedback with a delay is, in general, more efficient than the immediate feedback; see, e.g., [1,5]. The effect is not large, it is mostly visible in laboratory-type experiments where all other factors are equalized - and it is not distinguishable in real classroom, when the inevitable differences between the groups mask this effect [3]. However, in the laboratory experiments, a slightly delayed feedback has a small but statistically significant advantage.

Why delayed feedback is somewhat better: what we do in this paper. In this paper, we show that the simple geometric model developed in [4] provides an explanation for this somewhat counter-intuitive fact.

\section{Our Explanation}

Geometric model: reminder. The main purpose of teaching is to bring the students from the original knowledge state $A$ (in which they do not know the class material) to the desired state $B$ (in which they have a good mastery of this material).

Ideally, the path to knowledge should be the shortest path from $A$ to $B$, the straight line connecting $A$ and $B$. In reality, due to misunderstandings and misconceptions, student deviate from the desired straight line $A B$ and follow a direction $A B^{\prime}$ which is somewhat different from the desired one.

This is where feedback helps: upon receiving feedback, students realize that they had some misconceptions, and thus, start moving towards the desired state $B$. In geometric terms, this means that instead of following the segment $A C$ of the ideal straight line $A B$, students first follow a straight line segment $A C^{\prime}$ from the original state $A$ to some point $C^{\prime} \neq C$, and then - after receiving the feedback - a straight line from $C^{\prime}$ to $B$.

Problem with immediate feedback. The instructors' experience enables them to detect small deviations. As a result, the instructor can see even minor differences between the desired direction $A C$ and the actual direction $A C^{\prime}$.

However, students are not yet that skilled. As a result, they may not understand the difference between the directions as indicated by the instructor. In other words, they may correct the specific things indicated by the instructor, but still do not realize the problems in their understanding that caused them to deviate from the desired path $A C$ to a slightly different path $A C^{\prime}$.

This is especially true if we follow the above-mentioned empirically supported recommendations and submit frequent intermediate feedback to students. If we submit the feedback at the time when the path $A C$ followed by the student was reasonably short, then a small deviation of angle $\alpha$ of the direction $A C^{\prime}$ from the desired direction $A C$ leads to a small deviation of the resulting state of the knowledge $C^{\prime}$ from the desired state $C$ : this deviation is approximately equal to $A C \cdot \alpha$. As a result, the distance $C C^{\prime} \approx A C \cdot \alpha$ from the actual 
state $C^{\prime}$ of the student's knowledge to the state $C$ corresponding to the ideal learning process is so small that a student may not notice the difference between the two states.

Delayed feedback helps improve the situation. If we delay the feedback by some time, then, by the time the student receives the feedback, he/she has already followed the original direction $A C^{\prime}$ even further, to some point $D^{\prime}$. As a student follows a straight line further that the point $C^{\prime}$, the distance $D D^{\prime}$ from the student's actual state $D^{\prime}$ and the desired state $D$ at this moment of time (corresponding to following the perfect learning trajectory $A B$ ) increases: it is now equal to $A D^{\prime} \cdot \alpha$, where $A D^{\prime} \approx A D$ is larger than $A C^{\prime} \approx A C$ - and the more we delay, the larger this difference becomes.

As the distance $D D^{\prime}$ increases, this distance becomes larger than the student's detection threshold - and thus, a student will clearly see the deviation and therefore correct it.

So, the existence of such a detection threshold explains why the delayed feedback often improves learning.

\section{Acknowledgments}

This work was supported in part by the National Science Foundation grant HRD-1242122 (Cyber-ShARE Center of Excellence).

\section{References}

[1] A. C. Butler and H. L. Roediger III, "Feedback enhances the positive effects and reduces the negative effects of multiple-choice testing", Memory and Cognition, 2008, Vol. 36, pp. 604-616.

[2] J. Epstein, "The calculus concept inventory measurement of the effect of teaching methodology in mathematics", Notices of the American Mathematical Society, 2013, Vol. 60, No. 8, pp. 1018-1026.

[3] J. A. Kulik and C. C. Kulik, "Timing of feedback and verbal learning", Review of Educational Research, 1988, Vol. 58, No. 1, pp. 79-97.

[4] O. Lerma, O. Kosheleva, and V. Kreinovich, "A Simple Geometric Model Provides a Possible Quantitative Explanation of the Advantages of Immediate Feedback in Student Learning", Geombinatorics, 2015, Vol. 25, No. 1, pp. $22-29$.

[5] H. L. Roediger III and A. C. Butler, "The critical role of retrieval practice in long-term retention", Trends in Cognitive Sciences, 2011, Vol. 15, No. 1, pp. 20-27. 